\title{
Comparing Transperineal Ultrasonography and Vaginal Examination for Discomfort in Labor Follow-up
}

\author{
Erdinç SARIDOĞANa \\ (1) Nursel ALP DAL \\ (1) Çağdaş ÖZDEMIRc \\ Erkan ŞiMŞEKa, \\ Özgür AĞLAMIŞc, \\ Burçin ÖZGÜd
}

${ }^{a}$ Clinic of Obstetrics \& Gynecology,

Tunceli State Hospital,

Tunceli, TURKEY

${ }^{b}$ Midwifery Department,

Munzur University Health High School,

Tunceli, TURKEY

'Clinic of Obstetrics \& Gynecology,

Çerkezköy State Hospital,

Tekirdağ, TURKEY

${ }^{d}$ Clinic of Obstetrics \& Gynecology,

University of Health Sciences

Zekai Tahir Burak Education and

Research Hospital,

Ankara, TURKEY

Received: 27.11.2018

Received in revised form: 24.12.2018

Accepted: 25.12.2018

Available online: 15.01.2019

\section{Correspondence:}

Erdinç SARIDOĞAN

Tunceli State Hospital,

Clinic of Obstetrics \& Gynecology,

Tunceli, TURKEY

erdinc_saridogan@hotmail.com

Copyright $\odot 2018$ by Türkiye Klinikleri

\begin{abstract}
Objective: This study aimed at knowing the difference between the pain scores of intrapartum transperineal ultrasonography and vaginal examination. Material and Methods: A total of 146 pregnant women who were in cephalic presentation and active phase of labor at term with low risk were evaluated prospectively by transperineal ultrasonography (TU) and vaginal examination (VE). The active phase of labor was accepted to be $5-6 \mathrm{~cm}$ of cervical dilatation, $>60 \%$ of cervical effacement, and $>250$ Montevideo units or at least three regular uterine contractions in ten minutes in cardiotocography. Descriptive characteristics and pain scores (using a visual analogue scale) were assessed. Results: The mean value of transperineal ultrasonography pain scores was $5.48 \pm 1.39$ (minimum 2 and maximum 8 ) and the mean value of vaginal examination pain scores was $7.12 \pm 1.28$ (minimum 4 to maximum 10$)(\mathrm{p}<0.001)$. The mean transperineal pain scores of nulliparous and multiparous women were $5.93 \pm 1.36$ and $5.15 \pm 1.32$, respectively $(\mathrm{p}<0.001)$. The mean vaginal examination pain scores of nulliparous women and multiparous women were $7.54 \pm 1.23$ and $6.82 \pm 1.24$, respectively $(\mathrm{p}<0.001)$. Conclusion: The use of ultrasonography in the follow-up of labor seems to be more acceptable and a less painful method.
\end{abstract}

Keywords: Labor pain; ultrasonography; pain measurement; visual analogue scale

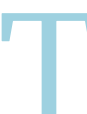
ransperineal ultrasonography (TU) is a method currently used in the follow-up of labor. The parameters such as the position of the fetal head, its descent, its distance to the perineum, the presence and size of caput succedaneum (CS), the grade of moulding and dilatation of cervix can be evaluated intrapartum and objectively. ${ }^{1-3}$

As in all areas of medicine, the comfort of the pregnant in the birth process, drug-free methods, and maternal friendly hospital philosophy are the main concerns. The objective is to reduce labor pain by avoiding the non-evidence based practices that increase the pain. We wonder whether the vaginal examination (VE) performed during this natural birth process provides benefits to the pregnant women or disturbs the natural birth process by discomforting women and causing negative emotional effects. Visual analogue scale (VAS), randomized controlled trials, and questionnaire have been used in recent years to find answers to these questions. ${ }^{4-6}$ In this study, we aimed to compare the degree of discomfort that caused by intrapartum VE and TU in pregnant women.

\section{MATERIAL AND METHODS}

After the approval of the Munzur University Human Research Ethics Committee, pregnant women who were admitted to the delivery unit of Tunceli 
State Hospital between October and December 2018 with the diagnosis of painful pregnancy in the period of 37-42 weeks gestation were included in the study. The study was conducted in accordance with the principles set forth in the Helsinki declaration in 2008. The active phase of labor was considered to be $5-6 \mathrm{~cm}$ of cervical dilatation, $>60 \%$ of cervical effacement and $>250$ Montevideo units or at least three regular uterine contractions in ten minutes in cardiotocography. ${ }^{7}$ Pregnant women with multiple pregnancies, non reassuring fetal status, suspect of chorioamnionitis, non-cephalic presentation or who had previous Cesarean delivery (CD) or $<37$ weeks gestation were excluded. The diagnosis of suspected intraamniotic infection was made when the maternal temperature was greater than or equal to $39.0^{\circ} \mathrm{C}$ or when the maternal temperature was $38.0-38.9^{\circ} \mathrm{C}$ and one additional clinical risk factor was present. ${ }^{8}$ Informed consent was obtained from all participating women before intrapartum evaluation was performed.

Different parameters, such as age, obstetric history, gestational week, and body mass index (BMI), were recorded for all participants. Ultrasonographic measurements were performed using a TOSHIBA Aplio MX (SSA-780A, Japan) ultrasound device by three obstetricians having 5-6 years of ultrasound experience (Dr. Erdinç Sarıdoğan, Dr. Çağdaş Özdemir, and Dr. Erkan Şimşek). The gel was applied to the probe before covering it with a glove in the dorsal lithotomy position with an empty bladder. The probe was placed between the labias in the mid-sagittal plane after applying the gel on the glove. The shortest distance between the maternal symphysis pubis and the fetal skull (head-symphysis distance, HSD), fetal head's progression distance under the maternal symphysis (head progression distance, HPrD), and size of CS were measured as described in the previous studies. ${ }^{9-12}$ No measurement lasted longer than one minute. Immediately after TU measurements, VE was performed by the delivery unit team, who did not perform ultrasonography and was not aware of the measurements. The clinical fetal head station (CFHS) was defined according to the maternal ischial spines. Both TU and VE were executed without uterine contraction.
After examinations, the pregnant women were asked to indicate the pain scores for TU and VE, respectively, on the VAS at a range of 0 to 10 . The weights and Apgar scores of the newborns were recorded after delivery.

Statistical analysis of the research data was performed using Statistical Package for Social Sciences (SPSS, Inc., Chicago, IL) Version 22. Descriptive characteristics were specified as minimum, maximum, median, number, ratio, mean, and standard deviation. TU and VE pain scores, their modes of delivery, pain scores according to CFHS and dilatation of cervix were compared. A p-value $<0.05$ was considered statistically significant for all statistics.

\section{RESULTS}

The descriptive characteristics of 146 pregnant women are shown in Table 1. The mean cervical dilatation was $7.66 \mathrm{~cm}$ (minimum 5 and maximum 10 ) and the mean cervical effacement was $79.1 \%$ (minimum 60\% and maximum 100\%). Of the pregnant women, $106(72.6 \%)$ were in the first stage and $40(27.4 \%)$ were in the second stage of labor. The median value of CFHS was 0 (minimum -3 and maximum +2 ). TU pain scores ranged from minimum of 2 to maximum of 8 with a mean value of $5.48 \pm 1.39$. VM pain scores ranged from minimum of 4 to maximum of 10 and the mean value was $7.12 \pm 1.28$ (Figure 1). Wilcoxon test showed that TU pain scores were significantly less than VM pain scores $(\mathrm{p}<0.001)$.

The mean TU pain score in the nulliparous group was $5.93 \pm 1.36$ and the mean TU pain score in the multiparous group was $5.15 \pm 1.32$. The mean VE pain score in the nulliparous group was $7.54 \pm 1.23$ and the mean VE pain score in the multiparous group was $6.82 \pm 1.24$. The differences between the pain scores of nulliparous and multiparous groups were found to be statistically significant by the Mann-Whitney U test ( $<<0.001$ and $p<0.001$, respectively).

As the CFHS and dilatation of cervix increased, there was no significant change in VE pain scores ( $\mathrm{p}=0.586$ vs. $\mathrm{p}=0.031$ ), on the other hand, the increase in TU pain scores was found to be significant via chi-square test $(\mathrm{p}=0.004$ vs. $\mathrm{p}<0.001)$. 


\begin{tabular}{|c|c|c|c|c|}
\hline Characteristics & Mean. $\mathrm{N}^{\star}$ or Median ${ }^{\star *}$ & Standart deviation & Range & Percent (\%) \\
\hline Age (years) & 27.53 & \pm 5.81 & $17-43$ & \\
\hline \multicolumn{5}{|l|}{ Parous } \\
\hline Nulliparous & $61^{*}$ & & & 41.8 \\
\hline Multiparous & $85^{\star}$ & & & 58.2 \\
\hline Gestational age (weeks) & 39.18 & \pm 1.21 & $37+0-41+4$ & \\
\hline $\mathrm{BMl}\left(\mathrm{kg} / \mathrm{m}^{2}\right)$ & 28.44 & \pm 4.26 & $18.2-46$ & \\
\hline Cervical dilatation $(\mathrm{cm})$ & 7.66 & & $5-10$ & \\
\hline Cervical effacement (\%) & 79.1 & & $60-100$ & \\
\hline CFHS & $0^{* *}$ & & $(-3)-(+2)$ & \\
\hline Pain score (U) & 5.48 & \pm 1.39 & $2-8$ & \\
\hline Pain score (VE) & 7.12 & \pm 1.28 & $4-10$ & \\
\hline VD & $132^{*}$ & & & 90.4 \\
\hline$C D$ & $14^{*}$ & & & 9.6 \\
\hline Weight of newborns (grams) & 3290.79 & \pm 359.31 & $2360-4780$ & \\
\hline $1^{\text {st }}$ minute Apgar score & $8^{* *}$ & & $6-9$ & \\
\hline $5^{\text {th }}$ minute Apgar score & $10^{* *}$ & & $8-10$ & \\
\hline
\end{tabular}

$\mathrm{N}$ : number, BMI: body mass index, cm: centimeters, CFHS: clinical fetal head station, kg: kilogram, m: meter, U: ultrasonography, VE: vaginal examination, VD: vaginal delivery, CD: Cesarean delivery.

Pregnant women included in the study were grouped according to the pain they felt during TU and VE. The women in group 1 had more pain during VE (\%67.8) and those in group 2 experienced equally intense pain during VE and TU (\%32.2). None of the women felt more intense pain during TU. The CD rate was $12.1 \%$ in the first group; however, the CD ratio in the second group was $4.4 \%$.

\section{CONCLUSION}

We conducted this study to determine if there were differences in discomfort between TU and VE in pregnant women during labor. As predicted, the ultrasonography performed with gentle pressure on the perineum was less painful than VE, in which we evaluated CFHS, fetal head position, and cervical dilatation. Although we did not perform ultrasonography during uterine contraction, none of the pregnant women stated that they did not feel pain during TU. This suggests that women have a prejudice about birth pain.

Labor pain continues to be one of the most worried issues during pregnancy and even directs some pregnant women to $\mathrm{CD}$. We use methods such as massage, suggestion, warm shower, music, birth ball,

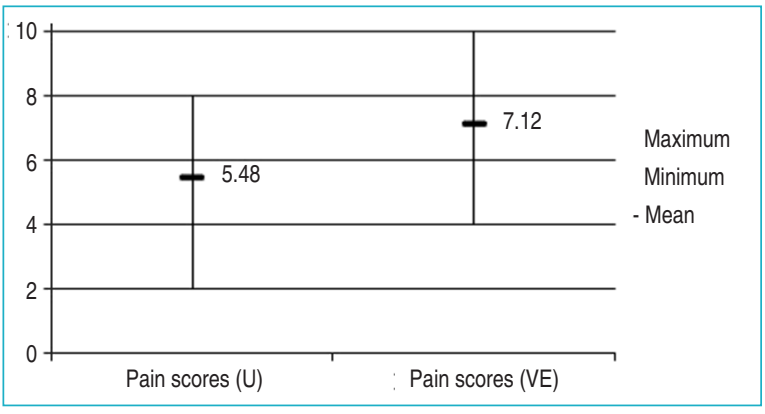

FIGURE 1: Range and the mean value of pain scores. U: ultrasonography, VE: vaginal examination.

and yoga to cope with labor pain in our clinic. ${ }^{13-15}$ As long as there is no medical indication, we do not recommend continuous electronic fetal monitoring. We help them in diverting attention from pain and concentrating on their baby at the end of the childbirth in order to have a satisfied birth process.

Pain during TU increased significantly as the CFHS and cervical dilatation increased but the pain during VE did not show a statistically significant difference. This is indicating that the pregnant women felt severe pain during VE regardless of the phase of labor. As a matter of fact, $95.9 \%$ of pregnant women had a pain score of 6 or above during VE. This rate was found to be $61 \%$ during TU. 
The CD ratio in the pregnant group, who stated that they felt equal pain during TU and VE, was higher than the pregnant group who said that they felt more pain during VE. This led us to think that the rate of $C D$ increases in the labor process as the female discomfort increases. Therefore, we avoided enema, urinary catheter, frequent VE, fundal pressure, intravenous fluid, intravenous medicine, perineum shaving, induction, amniotomy, episiotomy, continuous electronic fetal monitoring, and food and beverage restrictions to reduce the rate of $C D$ and health expenses. ${ }^{16,17}$

The primary CD ratio of the study is below than Turkey's average primary CD ratio. This may be due to (i) the fact that the study was conducted in a low risk pregnancy group, (ii) a high literacy rate in Tunceli, (iii) active working of Tunceli pregnancy unit, and (iv) following maternal friendly childbirth practices and natural birth methods in our clinic. The monthly primary $\mathrm{CD}$ ratio in Tunceli State Hospital in 2018 ranged from 8\% to $34 \%$. Considering these causes, the rate in this study that was $96 \%$ seems normal.

This study had certain limitation such as non-randomization and the lack of a questionnaire that can predict the discomfort in pregnant women.

The fact that TU and VM teams have similar years of experience in minimizing the TU and VE, which might have caused differences in the groups, is the strength of the study. Since pain is a relative concept, evaluating TU and VE on the same women raises the accuracy of the data by eliminating personal differences.

In conclusion, our study indicated that the majority of pregnant women felt less pain during TU compared to VE. The importance of ultrasonography in the follow-up of labor is enhanced by the fact that it offers objective findings to clinicians and increases the comfort to women.

Further extensive studies are needed to delineate the effect of intrapartum ultrasound.

\section{Source of Finance}

During this study, no financial or spiritual support was received neither from any pharmaceutical company that has a direct connection with the research subject, nor from a company that provides or produces medical instruments and materials which may negatively affect the evaluation process of this study.

\section{Conflict of Interest}

No conflicts of interest between the authors and / or family members of the scientific and medical committee members or members of the potential conflicts of interest, counseling, expertise, working conditions, share holding and similar situations in any firm.

\section{Authorship Contributions}

Idea/Concept: Erdinç Sarıdoğan, Çağdaş Özdemir; Design: Nursel Alp Dal, Erkan Şimşek; Control/Supervision: Erdinç Sarıdoğan, Burçin Özgü; Data Collection and/or Processing: Erdinç Sar1doğan, Çağdaş Özdemir, Erkan Şimşek; Analysis and/or Interpretation: Özgür Ağlamış, Burçin Özgü; Literature Review: Özgür Ağlamış, Erdinç Sarıdoğan; Writing the Article: Erdinç Sarıdoğan; Critical Review: Burçin Özgü; References and Fundings: Çağdaş Özdemir; Materials: Erkan Şimşek, Çağdaş Özdemir.

\section{REFERENCES}

1. Barbera AF, Pombar $X$, Perugino $G$, Lezotte DC, Hobbins JC. A new method to assess fetal head descent in labor with transperineal ultrasound. Ultrasound Obstet Gynecol 2009;33(3):313-9.

2. Hassan WA, Eggebø T, Ferguson M, Gillett A, Studd J, Pasupathy D, et al. The sonopartogram: a novel method for recording progress of labor by ultrasound. Ultrasound Obstet Gynecol 2014;43(2):189-94.

3. Malvasi A, Barbera A, Di Vagno G, Gimovsky A, Berghella V, Ghi T, et al. Asynclitism: a lit- erature review of an often forgotten clinical condition. J Matern Fetal Neonatal Med 2015;28(16):1890-4.

4. Chan YT, Ng KS, Yung WK, Lo TK, Lau WL, Leung WC. Is intrapartum translabial ultrasound examination painless? J Matern Fetal Neonatal Med 2016;29(20):3276-80.

5. Seval MM, Yuce T, Kalafat E, Duman B, Aker $\mathrm{SS}$, Kumbasar H, et al. Comparison of effects of digital vaginal examination with transperineal ultrasound during labor on pain and anxiety levels: a randomized controlled trial.
Ultrasound Obstet Gynecol 2016;48(6):695700.

6. Usman S, Barton H, Wilhelm-Benartzi C, Lees CC. Ultrasound is better tolerated than vaginal examination in and before labour. Aust $\mathrm{N}$ Z J Obstet Gynaecol 2018 Jul 19. Doi: 10.1111/ajo.12864. [Epub ahead of print].

7. American College of Obstetricians and Gynecologists; Society for Maternal-Fetal Medicine. Obstetric care consensus no. 1: safe preventation of the primary cesarean delivery. Obstet Gynecol 2014;123(3):693-711. 
8. Committee Opinion No. 712: intrapartum management of intraamniotic infection. Obstet Gynecol 2017;130(2):e95e101.

9. Gillboa Y, Kivilevitch Z, Spira M, Kedem A, Katorza E, Moran O, et al. Head progression distance in prolonged second stage of labor: relationship with mode of delivery and fetal head station. Ultrasound Obstet Gynecol 2013;41(4):436-41.

10. Hassan WA, Eggebo TM, Salvesen KA, Lindtjorn $E$, Lees $C$. Intrapartum assessment of caput succedaneum by transperineal ultrasound: a two-centre pilot study. Aust N Z J Obstet Gynaecol 2015;55(4):4013.

11. Tutschek B, Torkildsen EA, Eggebø TM. Comparison between ultrasound parameters and clinical examination to assess fetal head station in labor. Ultrasound Obstet Gynecol 2013;41(4):425-9.

12. Youssef A, Maroni E, Ragusa A, De Musso F, Salsi G, lammarino MT, et al. Fetal head-symphysis distance: a simple and reliable ultrasound index of fetal head station in labor. Ultrasound Obstet Gynecol 2013;41(4):41924.

13. Simavli S, Gumus I, Kaygusuz I, Yildirim M, Usluogullari B, Kafali $\mathrm{H}$. Effect of music on labor pain relief, anxiety level and postpartum analgesic requirement: a randomized controlled clinical trial. Gynecol Obstet Invest 2014;78(4):244-50.

14. Jahdi F, Sheikhan F, Haghani $H$, Sharifi B, Ghaseminejad A, Khodarahmian M, et al. Yoga during pregnancy: the effects on labor pain and delivery outcomes (A randomized controlled trial). Complement Ther Clin Pract 2017;27:1-4.

15. Tuncay S, Kaplan S, Moraloglu Tekin O. An assessment of the effects of hydrotherapy during the active phase of labor on the labor process and parenting behavior. Clin Nurs Res 2017;1:1054773817746893.

16. Çalik KY, Karabulutlu Ö, Yavuz C. First do no harm-interventions during labor and maternal satisfaction: a descriptive cross-sectional study. BMC Pregnancy Childbirth 2018;18(1): 415.

17. Bossano CM, Townsend KM, Walton AC, Blomquist JL, Handa VL. The maternal childbirth experience more than a decade after delivery. Am J Obstet Gynecol 2017;217(3):342. e1-e8. 